\title{
Using Generalized Additive Modelling to Understand the Drivers of Long-Term Nutrient Dynamics in the Broadwater Estuary (a Subtropical Estuary), Gold Coast, Australia
}

\author{
Russell Richards $^{\dagger}$, Milani Chaloupka ${ }^{\ddagger}$, Darrell Strauss ${ }^{\dagger}$, and Rodger Tomlinson ${ }^{\dagger}$ \\ ${ }^{\dagger}$ Griffith Centre for Coastal Management \\ Griffith University \\ Gold Coast, Queensland 4222, Australia \\ r.richards@griffith.edu.au \\ *Ecological Modelling Services Pty Ltd \\ P.O. Box 6150 \\ University of Queensland \\ St Lucia, Queensland 4067, Australia
}

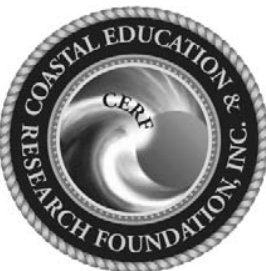

www.cerf-jcr.org

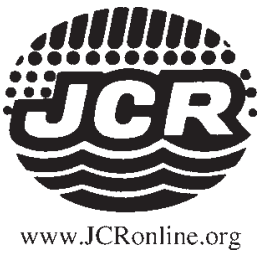

\section{ABSTRACT}

Richards, R.; Chaloupka, M.; Strauss, D., and Tomlinson, R., 0000. Using generalized additive modelling to understand the drivers of long-term nutrient dynamics in the Broadwater Estuary (a subtropical estuary), Gold Coast, Australia. Journal of Coastal Research, 00(0), 000-000. Coconut Creek (Florida), ISSN 0749-0208.

\begin{abstract}
Conclusions drawn from comparing short-term monitoring data with a baseline data set and water-quality guidelines need to be viewed in the context of numerous physical and biogeochemical mechanisms controlling nutrient concentrations within a system over long timescales. This paper highlights the use of generalized additive models (GAMs) to explore the functional relationships between four commonly used water-quality indicators (total nitrogen, total phosphorous, ammonia, nitrate) and a range of drivers including catchment inflow, wind speed, and tidal current. The results of this GAM assessment highlighted that nutrient concentrations within a subtropical estuary (Broadwater, Australia) is most dependent on catchment inflow. In particular, this assessment indicated the apparent importance of the Nerang River as a determinant of the nutrient concentrations observed in the Broadwater compared with the role of other tributaries, even though these other rivers provide the bulk of the freshwater flow into the system. This assessment also highlighted that the potential effects of monitoring location, tides, wind, and monitoring year need to be accounted for when framing the results of short-term data.
\end{abstract}

ADDITIONAL INDEX WORDS: Water quality, monitoring, statistical modelling, predictor and response variables

\section{INTRODUCTION}

The integrity of the coastal zone is increasingly coming under anthropogenic pressures such as urbanisation and population growth (Halpern et al., 2008; Nicholls et al., 2007; Van Dolah et al., 2008). Concomitant with these pressures is the need to manage coastal water quality effectively while preserving the environmental and socioeconomic elements that first attracted people to these areas. The Gold Coast area of SE Queensland, Australia is a good example of the challenges involved with managing a densely populated tourism area along a coastal fringe. Gold Coast City, which has a population of $c a$. half a million people, is the fastest growing region in Australia, attracting over 10 million visitors each year (Stuart et al., 2009) and consequently the pressure on this coastal zone is high.

Environmental processes often generate complex data that are multivariate and potentially nonlinear (Ferguson et al., 2008). Separating potentially confounding effects and contributing factors is an ongoing challenge in evaluating and managing water-quality data. Conclusions drawn from com-

DOI: $10.2112 /$ JCOASTRES-D-12-00190.1 received 24 September 2012; accepted in revision 11 February 2013; corrected proofs received 26 March 2013.

Published Pre-print online 10 April 2013.

(c) Coastal Education \& Research Foundation 2013 paring short-term monitoring data with a baseline data set and water-quality guidelines need to be viewed in the context of numerous physical and biogeochemical mechanisms controlling nutrient concentrations within a system over long timescales (Moss, Brodie, and Furnas, 2005). For example, estuarine nutrient concentrations are typically dependent on loading rates from surrounding catchments, atmospheric deposition, and from processes occurring within the system such as nitrification/denitrification, oceanic exchange, pelagicbenthic coupling, estuarine mixing gradients, biological uptake, and excretion (Burford et al., 2007; Eyre and McKee, 2002; Ferguson, Eyre, and Gay, 2004). Moreover, the contribution of these processes will vary, both spatially and temporally; they are often nonlinear and occur at a range of scales (Chang, 2008; Eyre and McKee 2002).

Various methods have been used in disentangling the mechanisms influencing estuarine nutrient dynamics, including mixing diagrams (Ferguson, Eyre, and Gay, 2004), rate measurements using benthic chambers (Ferguson, Eyre, and Gay, 2004), nutrient budgets (Eyre and McKee, 2002), sampling-computational approaches (Whiting et al., 1985), and deterministic models (Chapelle et al., 2000). We present here the use of generalized additive models (GAMs) (Hastie and Tibshirani 1986) to explore the functional relationships 


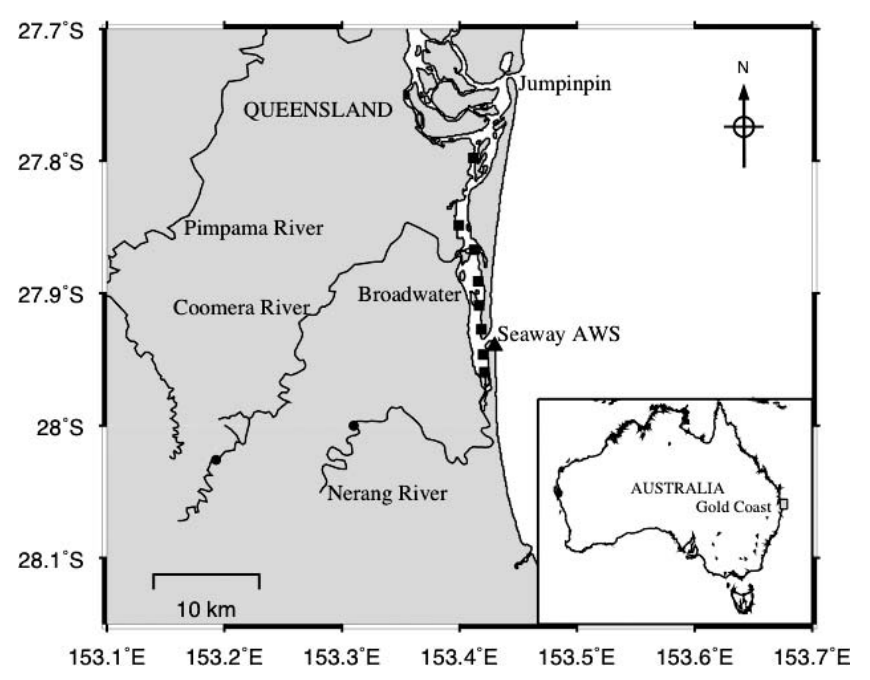

Figure 1. Location of the ecosystem health monitoring program sites ( $\square$ ), gauging stations $(\bullet)$, and meteorological weather station $(\boldsymbol{\Delta})$ used in this assessment.

between the nutrient concentrations measured during the long-term monitoring program (2000-2009) and a suite of selected covariates. GAMs are well suited for this application as demonstrated by their previous application to water-quality data (Bustamante et al., 2009; Siewicki et al., 2007). The fitted regression curves are nonparametric, making no a priori assumption about the form of the dependency of the response variable on the predictors that are selected. Furthermore, the response variable is not restricted to normal distributions and can be drawn from nonnormal distributions of the exponential family such as gamma, Poisson, and binomial. However, as with any regressive approach, care needs to be taken in specifying a GAM that coherently incorporates the important predictors while avoiding the development of an ill-conditioned model (Ramsay, Burnett, and Krewski, 2003; Wood 2008).

Overall, our aim is to develop and apply GAMs in exploring the functional relationships between commonly used waterquality indicators and a range of drivers influencing them. The objectives of this study are therefore twofold: (1) to highlight the utility of using GAMs to assess water-quality data sets and (2) to better understand the role, including eliciting the functional and potentially nonlinear relationship between predictor and response variables, of the various determinants involved.

\section{METHODS}

\section{Study Site}

The Gold Coast Broadwater is a large shallow estuary located in SE Queensland (Figure 1) and is connected to the Pacific Ocean by an approximately 250-m-wide and 11-m-deep navigational channel (the Seaway channel). The Seaway channel acts as a main transfer point for the exchange of biogeochemical constituents and water between the Broadwater and the Pacific Ocean (Mirfenderesk and Tomlinson
2007, 2008). The primary sources of freshwater into the Broadwater are the Coomera and Pimpama rivers to the NW with a lesser contribution from the Nerang River to the SW. The lower catchment area for the Broadwater is densely populated and is likely to receive significant nutrient loads from urban sources (Burton, Phillips, and Hawker, 2004).

\section{Water-Quality Data Set}

The data set used for the GAM assessment covers the period 2002-2009 and is a subset of nine sites (Figure 1) of the approximately 250 estuarine and marine monitoring sites throughout SE Queensland used by the Queensland Environmental Protection Agency for the Ecosystem Health Monitoring Program (EHMP). The EHMP (www.healthywaterways. org) is an ongoing assessment for all major catchments in the SE Queensland region and involves regular sampling of numerous physical and biochemical water-quality parameters including $\mathrm{pH}$, temperature, chlorophyll $a$, turbidity, conductivity, total $\mathrm{N}(\mathrm{TN})$, total $\mathrm{P}(\mathrm{TP}), \mathrm{N}$ oxides $\left(\mathrm{NO}_{x}\right)$, and $\mathrm{NH}_{3}$. Monitoring year, month, and nonvalidated monitoring time are also included in the EHMP data set. The quality of the monitoring data is supported by robust design and implementation of the monitoring program, strong quality-assurance and quality-control program, and ongoing performance assessment (Fisk, 2010).

The method of sampling during the EHMP encompasses the collection of surface water samples using a plastic bucket alongside the boat (triple prerinsed in sample water) with TN samples poured directly from the bucket into a $250-\mathrm{mL}$ plastic bottle (also prerinsed with sample water). Soluble nutrient samples are filtered under pressure through a $0.45-\mu \mathrm{m}$ membrane filter using a $60-\mathrm{mL}$ syringe (prerinsed in sample water). Samples are transported on ice in a dark insulated container to the laboratory where they are subsequently analysed using LACHAT $8000 \mathrm{QC}$ flow-injection analyser using photochemical methods.

\section{Statistical Analysis}

The utility of GAMs is that they allow a flexible specification of the dependence of a response variable on a set of covariates without having to specify the model in terms of detailed parametric relationships. Furthermore, they enable the response variable to be drawn from distributions of the exponential family other than a normal distribution, including the Poisson, binomial, and gamma. The form of a GAM follows Equation (1), where $g$ is a smoothing monotonic link function, $y_{i}$ is a response variable, $x_{i}$ and $z_{i}$ are some predictor variables, $f_{1}$ and $f_{2}$ are the smooth functions associated with each of the predictors, and $\varepsilon_{i}$ are independent error terms with a density function described by $N\left(0, \sigma^{2}\right)$. The model is fitted to the data by minimising the generalised cross-validation (GCV) score with the degree of smoothness of the model-terms part of the modelfitting process (Wood 2006).

$$
g\left(y_{i}\right)=f_{1}\left(x_{i}\right)+f_{2}\left(z_{i}\right)+\varepsilon_{i}
$$

\section{Specification of the GAM}

The formation of the initial GAM for each of the four nutrient types (TP, $\mathrm{TN}, \mathrm{NH}_{3}$, and $\mathrm{NO}_{x}$ ) is specified in Equation (2) and is based on current understanding of the expected dominant 
physical drivers of nutrient dynamics for the Broadwater. By starting with an appropriate model structure for the GAM we sought to facilitate meaningful results from the model-fitting process and also reduce the likelihood of model concurvity (Lefkaditou et al., 2008; Wood 2008). Model concurvity can lead to underestimation of variance and inflated type I errors (Ramsay, Burnett, and Krewski, 2003). This is especially relevant if using backfitting to fit the model rather than a direct GAM-fitting approach (Wood 2008) as is used here.

Rainfall-driven runoff is a known mechanism of nutrient loading into many receiving waters (Ferguson, Eyre, and Gay, 2004) and likely enters the Broadwater via the Coomera, Pimpama, and Nerang rivers (Mirfenderesk and Tomlinson 2007). Initially rainfall levels measured at the Australian Bureau of Meteorology automatic weather station (AWS) at the Gold Coast Seaway were trialled as a representation of catchment inflow to the Broadwater. However, preliminary model testing of the GAMs highlighted that rainfall was not a significant effect for any of the dependent variables even after the rainfall data was integrated over different periods (24 hours, 1 week, 1 month) so as to account for potential rainfall runoff lags. Subsequently, daily discharge flow rates recorded at gauging stations located on the Nerang River and Coomera River were obtained from the Queensland Department of Environment and Resource Management and used in the GAMs as a direct measure of catchment inflow. Note that discharge flow rates for the Pimpama River were not available. These discharge data were represented in the GAMs in six different ways during model testing: (1) 1-week accumulated flow for the Nerang River; (2) 1-week accumulated flow for the Coomera River; (3) 1-week accumulated flow for Nerang and Coomera rivers combined; (4) 2-week accumulated flow for the Nerang River; (5) 2-week accumulated flow for the Coomera River; and (6) 2-week accumulated flow for Nerang and Coomera rivers combined. These discharge flow totals are relative to the day of monitoring.

To account for the potential effect of wind-driven resuspension, which is a known mechanism of mobilising nutrients from the sediment to the water column in shallow estuaries (Simon 1989), 30-minute time-averaged wind speed and direction recordings at the Gold Coast Seaway were included in the data set. For each monitoring event, we selected the 30-minute wind recordings made before the EHMP monitoring time.

Tide-driven resuspension can also be a potentially significant driver of nutrient coupling between the benthos and the pelagic system (Ferguson, Eyre, and Gay, 2004). The Broadwater is strongly influenced by tidal exchange, with a residence time of approximately 5 days (Rasch et al., 2008), whereas current velocities up to $1.8 \mathrm{~m} \mathrm{~s}^{-1}$ can occur at the Seaway entrance (Dunn et al., 2012). In the absence of measured or modelled current velocities for the nine EHMP monitoring sites across the monitoring period (i.e. 2002-2009), we used interacting terms consisting of (1) the elapsed time between slack water, whether high or low, and monitoring time irrespective of whether there was ebb or flood tide occurring, and (2) a term representing the tidal range during which monitoring occurred. Observed correlation between tidal range and current strength at the Seaway channel (Dunn et al., 2012) supported this approach. To account for potential effects of tide direction we used a varying coefficient model (Hastie and Tibshirani 1993) to separate the tide effect for ebb and flood flows. A varying coefficient model enables interactions to be included in a GAM. Tide predictions for the Seaway were obtained from Maritime Safety department of the Queensland state government (Queensland Government 2009).

Year and month were included in the GAM because nutrient data may include underlying seasonal and long-term trends that are important considerations for nutrient management (Ferguson, Eyre, and Gay, 2004). Georeferenced site coordinates (latitude and longitude) used in the EHMP were also included to account for potential spatial effects.

$$
\begin{aligned}
& \text { Nutrient } \sim s(\text { year })+s(\text { month })+s(\text { inflow }) \\
& \quad+s(\text { tide since tide, range, by }=\text { ebb }) \\
& +s(\text { tide since tide, range, by }=\text { flood }) \\
& +s(\text { wind speed, wind direction })+s(\text { swell }) \\
& +s(\text { latitude, longitude })
\end{aligned}
$$

A quasilikelihood estimation approach with variance proportional to the mean was used for all models, whereas a logarithmic link function was specified to ensure positive predictions. Thin plate regression splines were used for all predictors except for month, where a cyclic cubic regression spline was specified to ensure consistency between the start and end points. To account for the dispersion in the data, locations of knots for the river inflow splines were based on quantiles derived directly from the flow data. Model selection was based on the GCV approach proposed for GAM assessments where the best-fit model is indicated by the lowest GCV score (Wood 2006). The significance of the nonparametric coefficients was assessed by whether their respective $p$-values were less than 0.05 (significant) or not (not significant). To test for overfitting of the data, the models were fitted to $90 \%$ of the data and the fitted model used to predict for the other $10 \%$ (Wood 2006). The model was implemented using the mgcv package in $\mathrm{R}$ (Wood 2006).

\section{RESULTS}

\section{Water Quality Summary Statistics}

A summary of the EHMP water-quality data for all sites throughout the Broadwater and for the specific EHMP site located closest to where each of the three tributaries (Nerang, Pimpama, and Coomera rivers) feeds into the Broadwater is presented in Table 1 . These summary statistics indicate that the concentrations (and variability) of $\mathrm{TN}, \mathrm{TP}, \mathrm{NH}_{3}$, and $\mathrm{NO}_{x}$ are similar throughout the Broadwater.

\section{Model Diagnostics}

Diagnostic plots for the best-fit models for each of the nutrient groups highlighted that the underlying assumptions of normality, independence, and constant variance in the residuals were satisfactory. These plots also supported the selection of a quasilikelihood variance with variance proportional to the mean. Tests for overfitting highlighted that the proportion of deviance explained for the fitted and the predicted model were consistent for all response variables and indicated that overfitting was not occurring. Autocorrela- 
Table 1. Average (1 SD) concentrations of total N (TN), total P (TP), $\mathrm{NH}_{3}$, and $\mathrm{NO}_{\mathrm{x}}$ for all Ecosystem Health Monitoring Program (EHMP) sites (Broadwater). Average (1 SD) concentrations also shown for the EHMP site closest to where the Nerang, Pimpama, and Coomera rivers enter the Broadwater. Units are $\mu$ g $L^{-1}$ for all nutrients.

\begin{tabular}{lcrr}
\hline \hline Nutrient & Broadwater & Nerang & Pimpama \\
\hline $\mathrm{TN}$ & $0.165(0.089)$ & $0.168(0.091)$ & $0.172(0.071)$ \\
$\mathrm{TP}$ & $0.018(0.010)$ & $0.017(0.010)$ & $0.021(0.008)$ \\
$\mathrm{NH}_{3}$ & $0.006(0.015)$ & $0.009(0.021)$ & $0.184(0.090)$ \\
$\mathrm{NO}_{x}$ & $0.009(0.038)$ & $0.013(0.040)$ & $0.022(0.010)$ \\
\hline
\end{tabular}

tion checks of the residuals for each best-fit model highlighted that error terms were independent.

\section{GAM Assessment of TN}

The best-fit GAM contained all covariates used in the initial model and explained $80 \%$ of the deviance with all predictor variables significant $(p<0.05)$. The model performed best (obtained the lowest GCV score) when the catchment inflow was represented by the 2-week accumulated flow data for the Nerang River. The plots for TN are shown in Figure 2 with the order of the nonparametric smooths reflecting the importance of predictors on the response variable. The effect of the Nerang River flow was characterised by a strong positive relationship with the response variable for flows up to $500,000 \mathrm{~m}^{3}$ (per fortnight), after which it switches to a negative relationship. The year effect showed a noticeable peak effect in 2004 and an overall downward trend over the monitoring period, whereas the effect of monitoring site location on TN decreased at higher latitudes. Monitoring month was characterised by a nonlinear smooth, highlighting peak positive effects for DecemberJanuary and July and a peak negative effect for March-May and August-September. The tide effect of TN, in particular the tidal range, appeared to be stronger (positive effect) for the ebb flow than the flood flow, whereas there was a broad positive effect of wind speed on TN but no obvious effect of wind direction.

\section{GAM Assessment of TP}

The best-fit GAM for TP contained all covariates used in the initial model and explained $73 \%$ of the deviance with all predictors significant $(p<0.05)$. The model performed best when the catchment inflow was represented by the combined flow from the Nerang and Coomera rivers, aggregated for the 1week period before each sampling event, although similar modelling results (on the basis of GCV scores) were obtained when using the Nerang River flow data (1-week and 2-week aggregated flow) only.

The smoother plots for TP are presented in Figure 3, with the order of the nonparametric smooths reflecting the importance of predictors on the response variable. The influence of river flow on the response variable was characterised by a strong positive effect. The effect of monitoring year on TP was characterised by a peak effect for 2004 . There was a noticeable relationship with the latitude component of the monitoring location in a similar manner observed for TN. The influence of wind speed appeared clearer than that of wind direction and was characterised by a broad positive effect. The effect of ebb tide on TP was not overly clear but suggested an increased effect when the time between high tide and monitoring was shorter. Conversely, the effect of flood tide on TP was much clearer and was characterised by an increased effect on TP when the elapsed time between low tide and monitoring was 34 hours and at tidal ranges of approximately 1-1.5 m. Finally, the effect of sampling month showed a sinusoidal pattern whereby higher TP concentration was expected at the start and end months of the calendar year and lower concentrations expected around May-August.

\section{GAM Assessment of Ammonia}

The best-fit GAM for ammonia $\left(\mathrm{NH}_{3}\right.$; Figure 4) contained all covariates used in the initial model and explained $88.1 \%$ of the deviance with all predictors significant $(p<0.05)$. The model performed best when the catchment inflow was represented by the flow from the Nerang and Coomera rivers, aggregated for the 1-week period before each sampling event.

The effect of river inflow on $\mathrm{NH}_{3}$ showed a strong positive effect over the range of almost all of the data in a similar manner to that observed for TP. The effect of monitoring year was characterised by an increasing effect on $\mathrm{NH}_{3}$ from 2000 to 2003 and a decreasing effect from 2003 to 2008 before falling sharply away in 2009. There was an indication of decreasing $\mathrm{NH}_{3}$ at monitoring sites located at lower latitudes than those located at higher latitudes, although this effect was not as apparent as observed for TN and TP. The interaction smoother plot for wind did not show any obvious influence on $\mathrm{NH}_{3}$ for most of the data, although contours shown at low (0-10 $\left.\mathrm{m} \mathrm{s}^{-1}\right)$ and high (40-50 $\mathrm{m} \mathrm{s}^{-1}$ ) wind speeds suggest that there might be a slight positive effect of wind speed in the intervening range (10-40 $\mathrm{m} \mathrm{s}^{-1}$ ). The smoother for monitoring month was strongly nonlinear, indicating a broad positive effect from September to February, a negative effect from February to June, and an additional 'peak' effect around July. There was not an obvious effect of ebb tidal flow on $\mathrm{NH}_{3}$, with most of the data located in a region of the contour map where there was no apparent gradient. However, there was an indication of an increased effect when the elapsed time (time since tide) was around 2-5 hours and the tidal range was above $1.5 \mathrm{~m}$. Conversely, there was a clear effect of flood tidal flow on $\mathrm{NH}_{3}$ characterised by an increasing effect as both tidal range and elapsed time increased.

\section{GAM Assessment of $\mathrm{NO}_{x}$}

The best-fit GAM for the oxides of $\mathrm{N}\left(\mathrm{NO}_{x}\right)$ contained all covariates used in the initial model and explained $93.5 \%$ of the deviance with all predictors significant $(p<0.05)$. As with TP, the model performed best when the catchment inflow was represented by the combined flow from the Nerang and Coomera rivers, aggregated for the 1-week period before each 

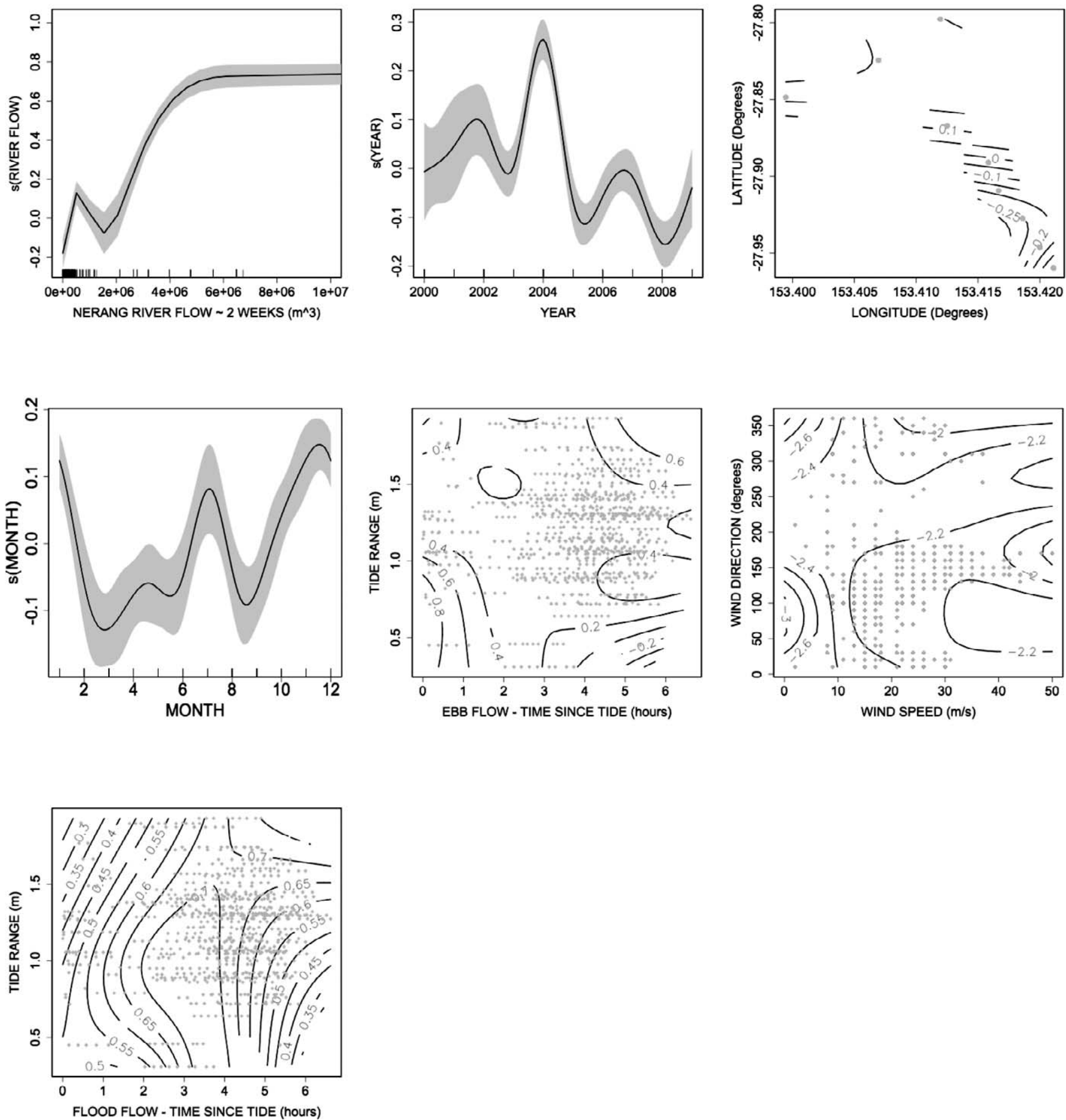

Figure 2. Smoother plots (in order from most significance) for best-fit model for total nitrogen. Note that catchment inflow data is based on 2-week accumulated hydrograph data for Nerang River. Note that longitude scale for spatial effect has been increased. Rug marks indicate location of data except for the interaction terms, where these are indicated by $\bullet$ on the smoother plot.

sampling event. Also similar to TP, similar modelling results (on the basis of GCV scores) were obtained when using the Nerang River flow data (1-week and 2-week aggregated flow) only.
The impact of flow (Nerang + Coomera rivers) on $\mathrm{NO}_{x}$ is similar to that observed for TP and $\mathrm{NH}_{3}$ and indicated a strong positive effect over most of the predictor data. Monitoring year had a strongly nonlinear functional re- 

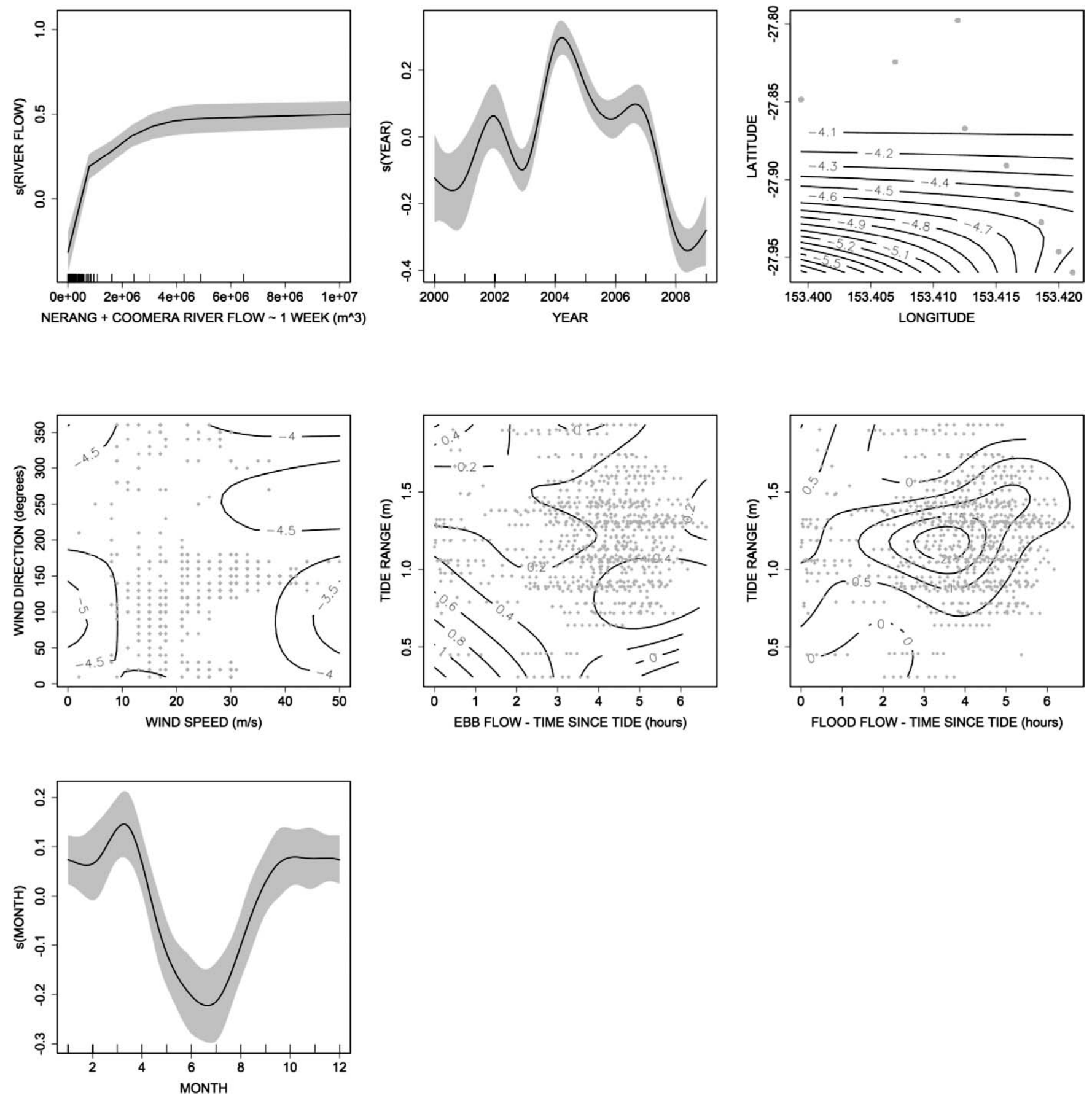

Figure 3. Smoother plots (in order from most significance) for best-fit model for total phosphorous. The catchment inflow data is based on 1-week accumulated hydrograph data for Nerang and Coomera rivers combined. Note that longitude scale for spatial effect has been increased. Rug marks indicate location of data except for the interaction terms, where these are indicated by $\bullet$ on the smoother plot.

sponse, although it can be broadly characterised as positive from 2000 to 2002 and decreasing from 2002 to 2009. The effect of monitoring site location on $\mathrm{NO}_{x}$ differed from that observed for the other three nutrients in that it decreased as latitude increased beyond the monitoring site located fourth from bottom in Figure 5. There was also an obvious functional response to longitude that also increased beyond this same monitoring site. The impact of wind on $\mathrm{NO}_{x}$ broadly reflected a positive effect of wind speed and direction below $c a .20 \mathrm{~m} \mathrm{~s}^{-1}$ and $150^{\circ}$ respectively and a negative effect above these 

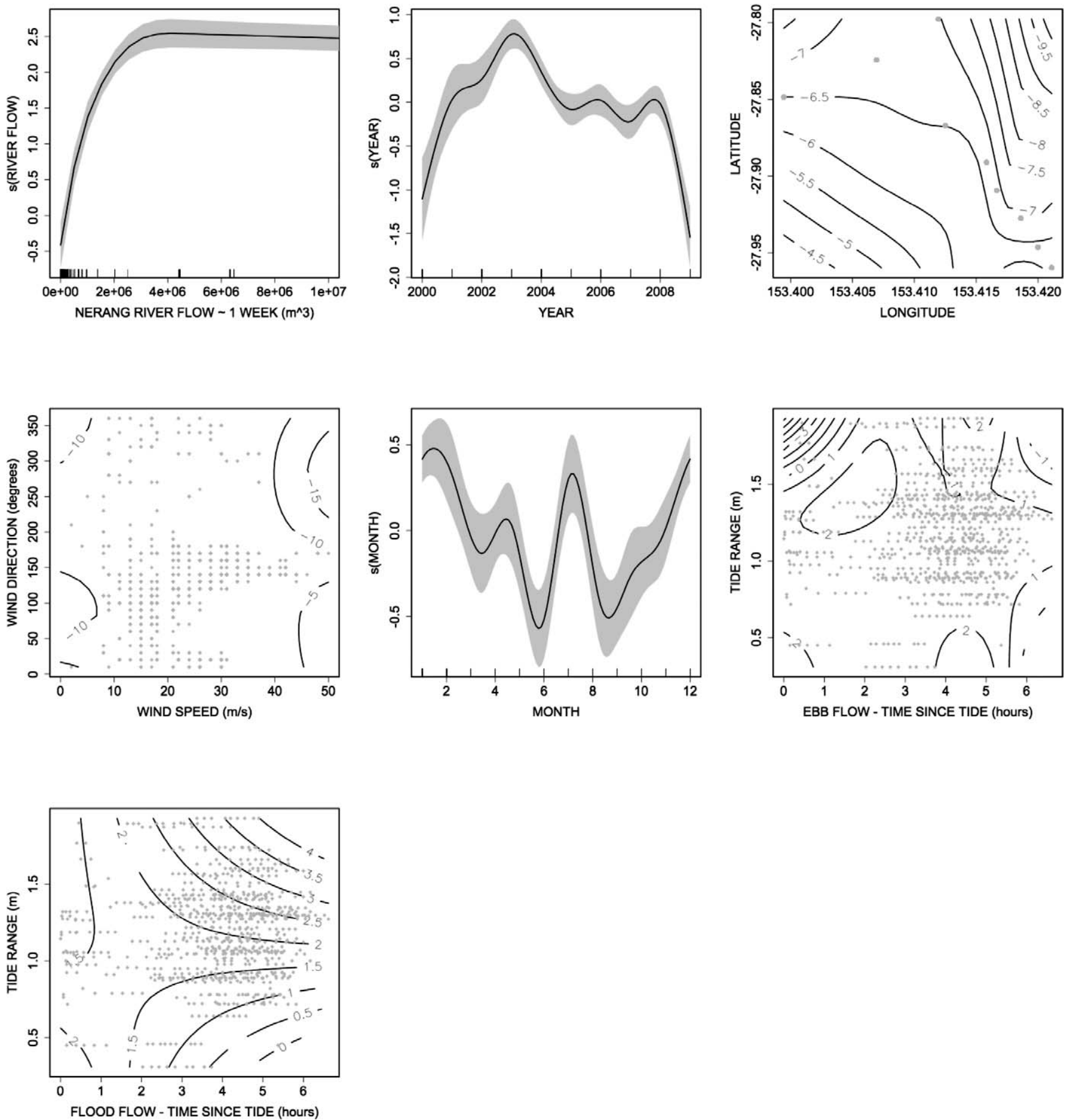

Figure 4. Smoother plots (in order from most significance) for best-fit model for ammonia. The catchment inflow data is based on 1-week accumulated hydrograph data for the Nerang River. Note that longitude scale for spatial effect has been increased. Rug marks indicate location of data except for the interaction terms, where these are indicated by $\bullet$ on the smoother plot.

thresholds. Ebb tide had an increased impact at elapsed time of $c a$. 3-5 hours and tidal range of 0.8-1.2 m, whereas the effect of flood tide was similar to that observed for $\mathrm{NH}_{3}$, increasing as both tidal range and elapsed time increased.
Finally, there was a nonlinear relationship between monitoring month and the response variables that peaks (positively) for April and for September-November and negatively for February and June. 

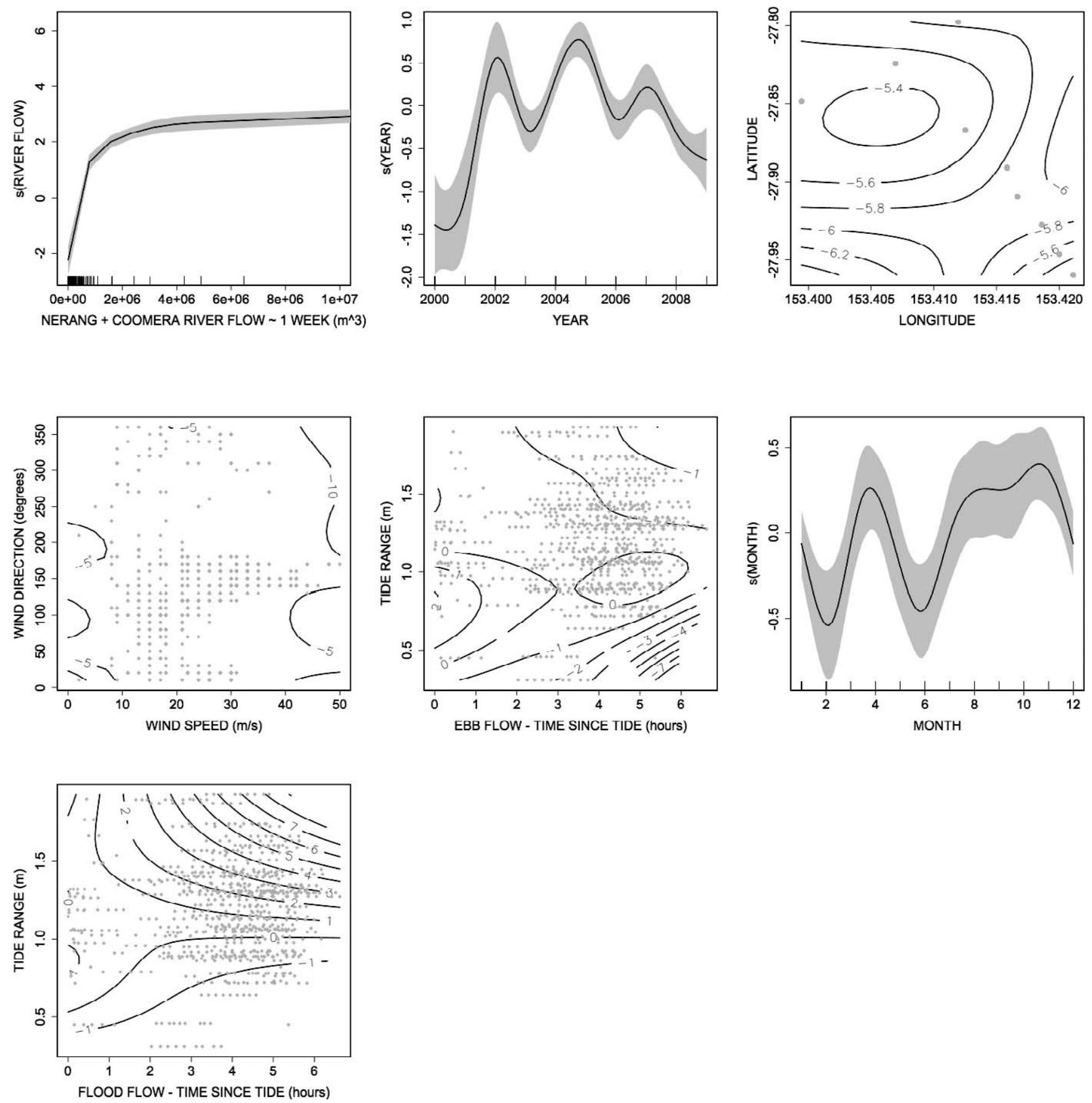

Figure 5. Smoother plots for best-fit model for $\mathrm{NO}_{x}$. The catchment inflow data is based on 1-week accumulated hydrograph data for the Nerang and Coomera rivers combined. Note that longitude scale for spatial effect has been increased. Rug marks indicate location of data except for the interaction terms, where these are indicated by $\bullet$ on the smoother plot.

\section{DISCUSSION}

We have undertaken a GAM assessment of a water-quality data set (2000-2009) collected in the Broadwater Estuary, Gold Coast, Australia. Such an understanding is important for providing a better understanding of the key determinants influencing nutrient concentrations within the system and for contextualising the results that emerge from shorter-term monitoring programs that are focused on specific water-quality management issues. 


\section{Effect of Catchment Inflow}

A major outcome of this study was identifying the role of catchment river inflow in influencing nutrient concentrations in the Seaway channel. The prominence of freshwater loading as a major mechanism is not surprising given that in subtropical catchments, runoff is often a significant vector of nutrient input to estuaries, potentially accounting for $80-90 \%$ of their annual load (Eyre, 1995). What is perhaps surprising is that the four nutrient types seem more influenced by the 'smaller' Nerang River inflow than by the Coomera River, even though the latter has a much larger flow volume. This supposition that the Nerang River provides smaller discharge to the Broadwater than the Coomera and Pimpama rivers, which are located to the north of the Broadwater (Figure 1), is based on the findings of Mirfenderesk and Tomlinson (2007). They used a calibrated hydrodynamic model to estimate that $70 \%$ of the the discharge through the entrance of the Broadwater flows southward through a northern channel from the Coomera and Pimpama rivers, whereas the Nerang system contributes only ca. $16 \%$ to the total discharge. Comparing the streamflow data recorded at the gauging stations, the average daily inflow from the Nerang River $\left(105,500 \mathrm{~m}^{3} \mathrm{~d}^{-1}\right)$ is much higher than that for the Coomera River $\left(31,989 \mathrm{~m}^{3} \mathrm{~d}^{-1}\right)$. This might suggest that the Nerang River has a greater discharge into the Broadwater than the Coomera River and is therefore indicative of why the Nerang River appears to be more influential on the nutrient concentrations. However, the discharge volume that ultimately enters the Broadwater will depend largely on the catchment runoff that enters these rivers downstream of their respective gauging stations.

Given the absence of available hydrograph data for the Pimpama River, we were unable to test the potential effects of this input on nutrient dynamics within the system. However, it is noted that the lower reaches of the Pimpama River, and to a lesser extent the Coomera River, consist of large areas of grassland, whereas the lower reaches of the Nerang River is urbanised, featuring several canal estates. Urbanised landscapes have been linked to higher nutrient loadings than nonurbanised landscapes (Jeng et al., 2005) and in particular those with canals (Birch and Taylor 1999; Burton, Phillips, and Hawker, 2004).

\section{Temporal Trends}

Important underlying annual trends were also identified in the long-term nutrient data, providing compelling evidence that monitoring year itself is an important determinant of observed nutrient concentrations in the Broadwater. The prevalence of a strong annual trend in the data has implications for comparing short-term water-quality monitoring data against baseline concentrations such as those provided here using the EHMP data or against water-quality guidelines (e.g. ANZECC 1992). It also supports the recommendation of Moss, Brodie, and Fusna (2005) that monitoring programs need to be carried out for a substantial period to account for potentially confounding long-term metrical effects.

A common feature for TN, TP, and $\mathrm{NH}_{3}$ was a peak effect around 2003-2004 compared with the other monitoring years. It was not clear why this is the case but it could reflect changes in land use management, which would influence the nutrient loading into the Broadwater. It might also reflect, at least partially, that the recorded annual rainfall (measured at the Seaway AWS) was highest in 2004. Additionally, the period 2002 to 2004 was characterised as a period of generally negative Southern Oscillation Index values (Australian Bureau of Meteorology www.bom.gov.au) indicating El Niño conditions. However, under these conditions the east coast of Australia is more likely to have experienced drier conditions (Chiew et al., 1998).

The effect of monitoring month was also significant for the four nutrient classes, although it was consistently less important than the annual effect. The associated smoother was also characterised by strong nonlinearity, especially for $\mathrm{TN}, \mathrm{NH}_{3}$, and $\mathrm{NO}_{x}$, that made it difficult to describe the functional relationship it had with the response variables. However, there was some consistency in that the month effect was generally positive at the start and end of the calendar year. The positive effect toward the end of the year could reflect the seasonal pattern for rainfall, which the Gold Coast Seaway AWS shows is historically higher from October to December than at other times. A biological signal might be expected to manifest itself in terms of increased nutrient cycling in warmer months (November-February) and decreased cycling in cooler months (May-August), especially for $\mathrm{NH}_{3}$ and $\mathrm{NO}_{x}$, which are important for microalgal growth. Chlorophyll $a$ concentrations in the Broadwater are typically higher around January-March (www.healthywaterways.org) and might therefore account for the positive effect at the start of the year that was generally observed in the smoothers for 'month'.

\section{Spatial Trends}

Monitoring site location was shown to be a significant predictor in all four GAMs, translating into a broad S-N effect on the nutrients for $\mathrm{TN}, \mathrm{TP}$, and $\mathrm{NH}_{3}$ and less so for $\mathrm{NO}_{x}$. This provides further supporting evidence that the Nerang River to the south is a major source of nutrients in the Broadwater rather than the tributaries to the north. The Broadwater entrance (Seaway) is the location for discharge of recycled wastewater on the ebb flow (Dunn et al., 2012; Stuart et al., 2009), which would tend to facilitate increased dissolved nutrients toward the southern limits of the study area. Sediment analysis also indicates higher total Kjeldahl N, $\mathrm{NH}_{4}$, and $\mathrm{NO}_{x}$ concentrations in the southern area of the Broadwater compared with the north (Burton, Phillips, and Hawker, 2004).

\section{Wind and Tide Effects}

We observed strong effects associated with wind and tide across the four nutrient classes. Vertical mixing and resuspension due to wind and tidal currents are known to influence pollutant dispersal in shallow estuaries (Birch and Hogg 2010; Booth et al., 2000), especially where there are rich nutrientbearing sediments such as those present in the Broadwater (Burton, Phillips, and Hawker, 2004). The Broadwater is characterised by strong tidal flows, exchanging approximately 100 GL through the Seaway during each day (Rasch et al., 2008), although it has been shown that large quantities of underlying sediment in shallow waterways can be resuspended by relatively low wind speeds $(<15 \mathrm{~km} / \mathrm{h}$ ) (Booth et al., 2000). Furthermore, the mobility of TN and TP may be different from 
the dissolved inorganic nutrients $\left(\mathrm{NH}_{4}\right.$ and $\left.\mathrm{NO}_{x}\right)$ because of different biogeochemical characteristics. TN and TP will likely be dominated by particulate forms and therefore resuspension and deposition will be driven by particulate size, whereas the dissolved nutrients will be influenced more by diffusion and mixing processes along with coastal upwelling (Turner and Millward 2002). Finally, on the basis of the GAMs, ebb flow appeared to be more influential on nutrient levels than the flood flow. This might reflect the role of discharging recycled wastewater at the Broadwater entrance during the ebb cycle only (Stuart et al., 2009).

\section{CONCLUSIONS}

In summary, this GAM assessment has demonstrated how long-term monitoring data can be combined with meteorological and hydrological data to provide information regarding the significance and form of the functional relationships between nutrient concentrations and a suite of covariates. In particular, this assessment highlighted the apparent importance of the Nerang River as a determinant of the nutrient concentrations observed in the Broadwater compared with the role of other tributaries, even though these other rivers provide the bulk of the freshwater flow into the system. The cessation of recycled water discharge into the Nerang River in 1994 has seen improvement in the nutrient concentrations in the river (GCCC 2002). However, increased residential development in the middle and lower catchment areas (including canal estates) coupled with the presence of grazing and intensive agriculture in the upper catchment area appears to have (over time) offset any benefits associated with diverting the recycled water discharge.

This assessment also highlighted that the potential effects of monitoring location, tides, wind, and monitoring year need to be accounted for when framing the results of short-term data. If these potential effects are not accounted for then implications include the over- or underestimation of the significance of the data when compared with water-quality guidelines (e.g. ANZECC 1992) or other water-quality data sets in common areas (e.g. Dunn et al., 2012). Overall, GAMs can provide an effective method of understanding water-quality data sets from multiple monitoring programs and elucidating the importance of spatiotemporal predictors. However, we also caution that direct statistical comparisons of data sets through prediction is not a panacea and that they maybe have more utility in being used to inform process-based models that can then be used as a basis for predictions.

\section{ACKNOWLEDGMENTS}

Gold Coast Water provided the funding for this assessment as part of the SmartRelease project. Healthy Waterways Partnership, Queensland Department of Environment and Resource Management and Australian Bureau of Meteorology are acknowledged for the provision of the EHMP, hydrograph, and wind data respectively.

\section{LITERATURE CITED}

ANZECC (Australian and New Zealand Environment and Conservation Council), 1992. Australian Water Quality Guidelines for Fresh and Marine Waters, National Water Quality Management Strategy.
Canberra, Australia: Australian and New Zealand Environment and Conservation Council, 314p.

Birch, G. and Taylor, S., 1999. Source of heavy metals in sediments of the Port Jackson estuary, Australia. Science of the Total Environment, 227(2-3), 123-138.

Birch, G.F. and Hogg, T.D., 2011. Sediment quality guidelines for copper and zinc for filter-feeding estuarine oysters? Environmental Pollution, 159(1), 108-115.

Booth, J.G.; Miller, R.L.; McKee, B.A., and Leathers, R.A., 2000.Wind-induced bottom sediment resuspension in a microtidal coastal environment. Continental Shelf Research, 20(7), 785-806.

Burford, M.A.; Johnson, S.A.; Cook, A.J.; Packer, T.V.; Taylor, B.M., and Townsley, E.R., 2007. Correlations between watershed and reservoir characteristics, and algal blooms in subtropical reservoirs. Water Research, 41(18), 4105-4114.

Burton, E.D.; Phillips, I.R., and Hawker, D.W., 2004. Trace metals and nutrients in bottom sediments of the Southport Broadwater, Australia. Marine Pollution Bulletin, 48(3-4_, 378-402.

Bustamante, J.; Pacios, F.; Díaz-Delgado, R., and Aragonés, D., 2009. Predictive models of turbidity and water depth in the Doñana marshes using Landsat TM and ETM+ images. Journal of Environmental Management, 90(7), 2219-2225.

Chang, H., 2008. Spatial analysis of water quality trends in the Han River basin, South Korea. Water Research, 42(13), 3285-3304.

Chapelle, A.; Menesguen, A.; Deslos-Paoli, J.M.; Souchu, P.; Mazouni, N.; Vaquer, A., and Millet, B., 2000. Modelling nitrogen, primary production and oxygen in a Mediterranean lagoon. Impact of oyster farming and inputs from the watershed. Ecological Modelling, 127(2-3), 161-181.

Chiew, F.H.S.; Piechota, T.C.; Dracup, J.A., and McMahon, T.A., 1998. El Nino/Southern Oscillation and Australian rainfall, streamflow and drought: links and potential for forecasting. Journal of Hydrology, 204(1-4), 138-149.

Dunn, R.J.K.; Catterall, K.; Hollingsworth, A.; Kirkpatrick, S.; Capati, G.; Hudson, S.; Khan, S.; Panther, J.; Stuart, G.; Szylkarski, S.; Teasdale, P.R.; Tomlinson, R.B., and Welsh, D.T., 2012. Short-term variability of nutrients and faecal indicator bacteria within the Gold Coast Seaway, southern Moreton Bay (Australia). Journal of Coastal Research, 28(1A), 80-88.

Eyre, B.D., 1995. A first-order nutrient budget for the tropical Moresby Estuary and catchment, North Queensland, Australia. Journal of Coastal Research, 11(3), 717-732.

Eyre, B.D. and McKee, L.J., 2002. Carbon, nitrogen, and phosphorus budgets for a shallow subtropical coastal embayment (Moreton Bay, Australia). Limnology and Oceanography, 47(4), 1043-1055.

Ferguson, A.; Eyre, B., and Gay, J., 2004. Nutrient cycling in the subtropical Brunswick Estuary, Australia. Estuaries, 27(1), 1-17.

Ferguson, C.A.; Carvalho, L.; Scott, E.M.; Bowman, A.W., and Kirika, A., 2008. Assessing ecological responses to environmental change using statistical models. Journal of Applied Ecology, 45(1), 193203.

Fisk, G., 2010. EHMP Report Review. BMT WBM Pty Ltd, July 2010 www.healthywaterways.org/media/scripts/doc_download.aspx? did $=1654$.

GCCC (Gold Coast City Council), 2002. Health of the Gold Coast Waterways. Queensland, Australia: Gold Coast City Council. www. goldcoast.qld.gov.au/health-of-the-gold-coast-waterways-report4936.html.

Halpern, B.S.; Walbridge, S.; Selkoe, K.A.; Kappel, C.V.; Micheli, F.; D’Agrosa, C.; Bruno, J.F.; Casey, K.S.; Ebert, C.; Fox, H.E.; Fujita, R.; Heinemann, D.; Lenihan, H.S.; Madin, E.M.P.; Perry, M.T.; Selig, E.R.; Spalding, M.; Steneck, R., and Watson, R., 2008. A global map of human impact on marine ecosystems. Science, 319(5865), 948-952.

Hastie, T. and Tibshirani, R., 1986. Generalized additive models. Statistical Science, 1(3), 297-310.

Hastie, T. and Tibshirani, R., 1993. Varying-coefficient models. Journal of the Royal Statistical Society: Series B, 55(4), 757-796.

Jeng, H.A.C.; Englande, A.J.; Bakeer, R.M., and Bradford, H.B., 2005. Impact of urban stormwater runoff on estuarine environmental quality. Estuarine, Coastal and Shelf Science, 63(4), 513-526. 
Lefkaditou, E.; Politou, C.-Y.; Palialexis, A.; Dokos, J.; Cosmopoulus, P., and Valavanis, V.D., 2008. Influences of environmental variability on the population structure and distribution patterns of the short-fin squid Illex coindetii (Cephalopoda: Ommastrephidae) in the eastern Ionian Sea. Hydrobiologia, 612(1), 71-90.

Mirfenderesk, H. and Tomlinson, R., 2007. Numerical modelling of tidal dynamic and water circulation at the Gold Coast Broadwater, Australia. In: Lemckert, C.(ed.), Proceedings of the 9th International Coastal Symposium, Journal of Coastal Research, Special Issue No. 50, pp. 277-281.

Mirfenderesk, H. and Tomlinson, R., 2008. Observation and analysis of hydrodynamic parameters in tidal inlets in a predominantly semidiurnal regime. Journal of Coastal Research, 24(5), 12291239.

Moss, A.; Brodie, J., and Furnas, M., 2005. Water quality guidelines for the Great Barrier Reef World Heritage Area: a basis for development and preliminary values. Marine Pollution Bulletin, $51(1-4), 76-88$.

Nicholls, R.J.; Wong, P.P.; Burkett, V.R.; Codignotto, J.O.; Hay, J.E.; McLean, R.F.; Ragoonaden, S., and Woodroffe, C.D., 2007. Coastal systems and low-lying areas. Climate change 2007: impacts, adaptation and vulnerability. In: Parry, M.L.; Canziani, O.F.; Palutikof, J.P.; van der Linden, P.J., and Hanson, C.E. (eds.), Contribution of Working Group II to the Fourth Assessment Report of the Intergovernmental Panel on Climate Change. Cambridge, U.K.: Cambridge University Press, pp. 315-356.

Queensland Government, 2009. Maritime Safety Queensland. www. msq.qld.gov.au/Tides/Purchase-information.aspx.

Ramsay, T.O.; Burnett, R.T., and Krewski, D., 2003. The effect of concurvity in generalized additive models linking mortality to ambient particulate matter. Epidemiology, 14(1), 18-23.

Rasch, P.S.; Khan, S.; Davies, S., and Capati, B., 2008. Assessing the assimilative capacity of an estuary using $2 \mathrm{D}$ and $3 \mathrm{D}$ modelling-
Gold Coast Broadwater Capacity Study. Engineers Australia 9th National Conference on Hydraulics in Water Engineering. Darwin, pp. 290-297.

Siewicki, T.C.; Pullaro, T.; Pan, W.; McDaniel, S.; Glenn, R., and Stewart, J., 2007. Models of total and presumed wildlife sources of fecal coliform bacteria in coastal ponds. Journal of Environmental Management, 82(1), 120-132.

Simon, N.S., 1989. Nitrogen cycling between sediment and the shallow-water column in the transition zone of the Potomac River and Estuary. II. The role of wind-driven resuspension and adsorbed ammonium. Estuarine, Coastal and Shelf Science, 28(5), 531-547.

Stuart, G.; Hollingsworth, A.; Thomsen, F.; Szylkarski, S.; Khan, S.; Tomlinson, R.; Kirkpatrick, S.; Catterall, K., and Capati, B., 2009 Gold Coast Seaway SmartRelease decision support system: optimising recycled water release in a sub tropical estuarine environment. Water Science and Technology, 60(8), 2077-2084.

Turner, A. and Millward, G.E., 2002. Suspended particles: their role in estuarine biogeochemical cycles. Estuarine, Coastal and Shelf Science, 55(6), 857-883.

Van Dolah, R.F.; Riekerk, G.H.M.; Bergquist, D.C.; Felber, J.; Chestnut, D.E., and Holland, A.F., 2008. Estuarine habitat quality reflects urbanization at large spatial scales in South Carolina's coastal zone. Science of the Total Environment, 390(1), 142-154.

Whiting, G.J.; McKellar, H.N., Jr.; Kjer, B., and Spurrier, J.D., 1985. Sampling and computational design of nutrient flux from a southeastern U.S. saltmarsh. Estuarine, Coastal and Shelf Science, $21(2), 273-286$.

Wood, S.N., 2006. Generalized Additive Models: An Introduction with $R$. London: Chapman \& Hall.

Wood, S.N., 2008. Fast stable direct fitting and smoothness selection for generalized additive models. Journal of the Royal Statistical Society: Series B, 70(3), 495-518. 